\title{
ESCRAVISMO NO BRASIL: \\ UM CONVITE À REFLEXÃO E AO DEBATE
}

\author{
LUNA, Francisco Vidal; KLEIN, Herbert S. Escravismo no Brasil. São \\ Paulo: EDUSP/Imprensa Oficial do Estado de São Paulo, 2010. 400p.
}

\begin{abstract}
$N_{\text {os tempos das pesquisas monográ- }}$ ficas, das histórias esmigalhadas, dos apertados prazos de redação de teses e de dissertações e de execução de projetos de pesquisa, escrever um ensaio interpretativo sobre a escravidão no Brasil, calcado em bibliografia e documentação sólidas, requer uma vastíssima experiência - décadas - em estudos na área. Com todos os riscos de tal empreitada, o mais interessante, e talvez paradoxal, é que foi realizada por autores atualmente ausentes dos quadros funcionais ativos da universidade brasileira, mas indispensáveis aos estudiosos do tema. Refiro-me a Francisco Vidal Luna e Herbert Klein, autores do recente Escravismo no Brasil, publicado entre nós em 2010 e, originalmente, em inglês, em 2009, com o título Slavery in Brazil. Além da grande capacidade de síntese, o mérito da obra é ímpar por versar, em uma linguagem acessível a estudantes e tam-
\end{abstract}

bém ao grande público, sobre assuntos afeitos a especialistas das histórias demográfica, econômica e serial. Síntese dessa monta seria impossível sem o crescimento, com qualidade, de pesquisas historiográficas brasileiras, inclusive nossas teses e dissertações, o que é repetidamente reconhecido pelos autores.

A parceria entre Luna e Klein não é nova, e tampouco suas perspectivas de sínteses, balanços e análises estruturais sobre a sociedade brasileira. Além de vários artigos, são coautores dos livros Slavery and the Economy of São Paulo (1750-1850), de 2003, Brazil since 1980 -traduzidos ao português com os títulos Evolução da sociedade e economia escravista de São Paulo, de 1750 a 1850 (2005) e $O$ Brasil desde 1980 (2007) - e Escravismo em São Paulo e Minas Gerais, de 2009, este último, em co-autoria com Iraci Del Nero Costa, premiado pela Academia 
Brasileira de Letras como o melhor livro em ciências sociais. Como se vê, o trabalho conjunto, orquestrado e harmônico desses autores traz grandes frutos para o conhecimento do Brasil.

Escravismo no Brasil alerta sobre o quanto se ganha com uma boa e bem documentada história demográfica e econômica, relegada em certos metiês acadêmicos, sob o rótulo infundado de ser uma história sem sujeito. Como afirma um dos fundadores da microhistória italiana, uma micro-análise "não fecha a porta à indagação serial. Serve-se dela". ${ }^{1}$ Assim, a obra também ensina o quanto se perde em minimizar o aparentemente simples fato de saber como e onde aportaram no Brasil os cativos africanos, quantos eram e de onde vieram, quem eram, quantos escravos aqui nasceram e casaram, quantos morreram, em que trabalhavam, como teciam elos sociais de compadrio etc. Tudo isso é imprescindível para conhecer melhor uma sociedade, e neste caso, especificamente, se trata de escravos, senhores, livres sem escravos, alforriados e seus descendentes, de brancos, pardos, pretos, os numerosos mestiços da sociedade escravista brasileira - enfim, são milhares e milhares os protagonistas do livro.

Não pense o leitor, porém, que estamos a lidar com generalidades.

Carlo Ginzburg, A micro-história e outros ensaios, Lisboa: Difel, 1991, p. 175.
Diversidade é a palavra-chave para entender o Escravismo no Brasil, na verdade os escravismos no Brasil. Não há nenhuma generalização apressada e o livro atenta sagazmente para as diferenças espaciais e temporais nas quais a escravidão se manifestou. Tão importantes são os motivos das diferenças, que estão longe de ter uma explicação única. Uma especificidade ali resultou de uma atividade econômica predominante, acolá da origem dos escravos, de sua demografia, das demandas do mercado externo e do interno, de fatores ecológicos, das condições africanas de oferta de cativos, dos preços do açúcar no mercado europeu, ou mesmo do incalculável coeficiente de paciência humana quando escravos disseram não às condições a que estavam submetidos etc. A ênfase em especificidades, porém, não é avessa a uma abordagem estrutural, como demonstram os autores.

A organização da obra em dez capítulos e uma conclusão obedece a uma lógica coerente, que conjuga "um arcabouço cronológico paralelamente a uma análise estrutural" ( $\mathrm{p}$. 10). A primeira parte, com cinco capítulos, trata dos movimentos, mas com um capítulo de síntese ao final: 1) "Origens da escravidão africana no Brasil"; 2) "O estabelecimento da escravidão africana no Brasil nos séculos XVI e XVII"; 3) “A escravidão e a economia no século XVIII"; 4) 
"A escravidão e a economia no século XIX”; e 5) "A economia da escravidão". A segunda parte aborda temas chaves na historiografia da escravidão em quatro capítulos: 6) "Vida, morte e migração na sociedade escrava afro-brasileira"; 7) "Resistência e rebelião no cativeiro"; 8) "Família, parentesco e comunidade"; e 9) "Pessoas livres de cor em uma sociedade escravista". Por fim, o único capítulo da última parte observa seu enunciado, 10) "A transição do cativeiro para a liberdade".

Portanto, pela análise e pelas questões que suscita, o livro provoca reflexões e debates.

O capítulo 1, em análise comparada, distingue a escravidão de outras formas de trabalho, ressaltando diferenças entre sociedades escravistas e sociedades com escravos, ou seja, a centralidade dos cativos nas primeiras e seu papel secundário nas segundas. Igualmente, salienta o impacto das sociedades atlânticas na formação da época moderna e da economia de mercado, sobretudo a partir das plantations açucareiras das ilhas dos Açores, Madeira e Canárias, ensaios para o que viria a ser a América portuguesa. Foi a partir daí que o sistema atlântico conjugou a escravidão e o tráfico de cativos como uma economia integrada, já que o "estabelecimento da colônia portuguesa no Brasil após 1500 marcaria o início da economia escravista de plantation nas
Américas, que tanto influenciaria os acontecimentos no hemisfério pelos quatro séculos seguintes" (p. 22). Os especialistas da história econômica e social poderão confrontar tal interpretação com as já clássicas sobre o papel da mão-de-obra indígena para a montagem inicial da plantation açucareira no Brasil, ${ }^{2}$ ou com obras recentes sobre outras sociedades escravistas nas Américas. ${ }^{3}$

Mas por que a opção por cativos africanos? Luna e Klein descartam como a-histórica a explicação, tão em voga hoje em dia, de ter sido por racismo dos europeus (p. 23). Prevaleceu o custo crescente dos cativos não africanos, por razões econômicas (menor custo do tráfico atlântico do que o saariano), por motivos políticos (pressão turca a partir do Levante e o consequente fechamento do acesso a cativos eslavos e balcânicos) etc. Em suma, "é possível explicar suficientemente a mudança para a mão-de-obra africana pelos critérios econômicos clássicos da restrição da oferta, dispensando-se explicações

2 Stuart B. Schwartz, Segredos internos: engenhos e escravos na sociedade colonial, 1550-1835, São Paulo: Companhia das Letras, 1988; John Manuel Monteiro, Negros da Terra: índios e bandeirantes nas origens de São Paulo, São Paulo: Companhia das Letras, 1994.

Russell R. Menard, Sweet Negotiations: Sugar, Slavery and Plantation Agriculture in Early Barbados, Charlottesville: University of Virginia Press, 2006. 
culturais para compreender essa dimensão de usar africanos" (p. 24). Todavia, por que europeus recorreram a africanos se havia índios nas Américas? Ainda que se reconheça o uso intenso de mão de obra indígena na América portuguesa, diferentemente do Peru e do México, os "índios do Brasil costeiro mostraram-se de difícil exploração por domínio indireto [...] não estavam habituados à tributação nem à atividade agrícola intensa" (pp. 25-26). Ao fim, por "diversas razões econômicas, políticas e até religiosas, os ibéricos acabaram abandonando a possibilidade da escravidão indígena" (p. 26). Tais afirmações dialogam com a análise de John Monteiro sobre São Paulo seiscentista e a de Stuart Schwartz sobre a Bahia de até meados do século XVII, sociedades escravistas que só abandonaram a escravidão indígena quando esta população se exauriu. $\mathrm{Ou}$ seja, não se trataria apenas das condições da oferta, mas, antes, da esfera da produção de mão-de-obra local. A reflexão está posta.

O capítulo 2 retoma o processo de uso massivo de mão-de-obra de origem africana, mas relacionando-o a atividades econômicas e a conjunturas políticas internacionais a partir da entrada no cenário atlântico de holandeses, franceses e ingleses. Assim, é salutar a abordagem dos impactos da União Ibérica (1580-1640) sobre a América portuguesa e sobre o sistema de plantation antilhano e caribenho, bem como a comparação entre os casos baiano e pernambucano. Por outro lado, insinua-se novamente o debate sobre o primum mobile (oferta ou demanda) do mercado do açúcar, no que os holandeses, como financiadores e como mercado desse produto brasileiro, foram cruciais. Talvez por isso, o capítulo não alude a importantes fontes de financiamento da atividade açucareira, ao menos, no caso baiano, ao papel central da Santa Casa de Misericórdia e dos comerciantes locais. Alijados do circuito do açúcar brasileiro com a reconquista de Pernambuco, os holandeses promoveram a fuga de capitais para as Antilhas, mas, já a partir de meados do século XVII, "a ascensão da economia escravista de grande lavoura nas Antilhas Francesas e Britânicas pôs fim à importância da Holanda [para a] produção e comercialização dos gêneros das plantations americanas" (p. 45). Mas o produto brasileiro não foi apagado dos circuitos internacionais, devido ao crescimento dos mercados europeu e doméstico e à qualidade do açúcar branco barreado. Em 1760, o Brasil ainda era o terceiro produtor mundial. O capítulo é lacunar para a segunda metade do século XVII, mas, antes, trata-se de uma lacuna historiográfica, pois há poucos trabalhos sobre o período. Sabe-se hoje, apenas, que no período da chamada "vi- 
ragem estrutural" do Império português, isto é, sua guinada para o Atlântico a partir de meados do século XVII e a bancarrota das finanças portuguesas, o número de engenhos fluminenses se expandiu, ainda que fosse uma atividade secundária frente à baiana e a pernambucana. ${ }^{4}$ Longe se estaria, portanto, de uma crise do século XVII. Eis mais um debate que o livro estimula.

O capítulo 3 trata do impacto econômico e demográfico das atividades mineradoras, sobretudo de Minas Gerais, sobre o conjunto da colônia, em particular o aumento estupendo do tráfico de cativos africanos. Sublinha os temas da estrutura de posse de escravos, da origem dos cativos, da reprodução natural da escravaria e de seus desequilíbrios demográficos. Atenta também para os senhores de cor, bem como a alta proporção de domicílios sem escravos. Finalmente, salienta o revivescimento açucareiro, o lugar do Brasil no mercado mundial e a diversificação econômica colonial. Tudo isso engendrou, no decorrer do século XVIII, uma demografia e uma sociedade singulares nas Américas, com forte presença de ne-

\footnotetext{
4 Ver, por exemplo, João Luís R. Fragoso, "A formação da economia colonial no Rio de Janeiro e de sua primeira elite senhorial", in J. L. R. Fragoso, M. de F. Gouvêa, e M. F. Bicalho (orgs). O Antigo Regime nos trópicos: a dinâmica imperial portuguesa (Rio de Janeiro: Civilização Brasileira, 2001), pp. 29-73.
}

gros e mestiços, escravos, libertos ou livres, inclusive como senhores de escravos. Contudo, boa parte da análise se baseia em fontes da segunda metade da centúria, quando o metal já não mais brilhava como antes. Essa lacuna não desmerece o capítulo. Antes, convida a refletir e estimula a investigação.

O capítulo 4 analisa os desdobramentos das transformações advindas da lavoura cafeeira, do revigoramento da produção açucareira e do pujante setor de alimentos, fatores que estimularam sobremaneira o tráfico externo e interno de cativos, respectivamente antes e depois de 1850 . Interessante é a forma como os autores tratam da escravaria na lavoura de exportação, principalmente a cafeeira, mas que jamais empregou a maioria absoluta dos escravos. Minas Gerais apresentava perfil de posse distinto de Rio de Janeiro e São Paulo, pois tinha muito mais senhores com menos escravos, mas, grandes ou pequenos os senhores, seus escravos estavam empregados em um mosaico de atividades laborais, ao contrário dessas outras províncias, onde a grande propriedade cafeeira empregava a maioria dos escravos nelas residentes. Por sua vez, o Nordeste e áreas do Sul do Brasil conjugaram muito bem trabalho escravo e trabalho livre. Em Pernambuco, por exemplo, "o crescimento da população livre de cor mais do que compensou 
essa queda [da população escrava], ocasionada em grande parte pela expansão do tráfico interno após 1850" (p. 100).

Passeia-se, assim, pelas várias modalidades do trabalho escravo, conjugadas ou não ao trabalho livre. No geral, Luna e Klein demonstram que, em "meados do século, menos da metade dos cativos residia nas três principais províncias cafeeiras [Rio de Janeiro, São Paulo e Minas Gerais], mas em 1872 mais da metade concentrava-se nessas regiões" (p. 122). A lacuna do capítulo talvez seja uma discussão da Lei de Terras, de 1850 , como parte integrante desse conjunto, mas apenas talvez, pois os autores estão convictos de que a abertura da fronteira agrária na vigência da escravidão tornava o trabalho o item principal na produção da riqueza social. Onde quer que estivessem, os cativos geralmente compunham a maior parcela da riqueza senhorial. Destarte, convida-se a refletir sobre que grupos sociais sustentaram a escravidão até bem avançado o Oitocentos, já que, apesar de mercantis e urbanas, as elites econômicas do Rio de Janeiro das décadas iniciais desse século tinham investido menos de $10 \%$ dos seus bens em escravos. ${ }^{5}$

João Luís R. Fragoso e Manolo Florentino, $O$ arcaísmo como projeto: mercado atlântico, sociedade agrária e elite mercantil no Rio de Janeiro, c. 1790 - c. 1840, Rio de Janeiro: Diadorim, 1993.
No capítulo 5, ponto alto do livro, ressalta-se que o Brasil escravista não era uma sociedade cindida entre antagonismos opostos: senhores de grandes escravarias, de um lado, e escravos, do outro. Ideia outrora presente em autores clássicos, incluindo Caio Prado Junior, Florestan Fernandes e Gilberto Freyre, que fizeram escola na historiografia brasileira. Todavia, Luna e Klein não jogam fora a criança junto com a água, pois de Freyre destacam o resgate da contribuição cultural dos cativos e de seus descendentes e a intensa mestiçagem. Aliás, muitos egressos do cativeiro estavam entre os senhores de pequenas escravarias. Mas quem e como agiam os vários tipos de senhores é, dentre outras, uma pergunta que o capítulo apenas convida a refletir em futuras pesquisas. A certeza é que, pela análise da estrutura de posse de escravos, no que os autores são pioneiros, o ponto de partida está dado. Mais do que isso, arriscam "um modelo interpretativo da escravidão no Brasil" (p. 133), usando como critérios os incentivos positivos e/ou o uso da violência na organização do trabalho. Associar tais aspectos à pluralidade de perfis senhoriais e à estrutura de posse de escravo é fundamental, ainda mais porque o "caso brasileiro mostra uma imensa diversidade de usos do escravo em outras áreas fora da grande lavoura. Além disso, encontramos produtores sem escra- 
vos em todos os tipos de atividade, com exceção do fabrico do açúcar. É essa diversidade no uso dos cativos e de produtores sem escravos a principal característica do escravismo brasileiro" (p. 138). Porém, não se estimulou o mercado de trabalho livre, tendo em vista a lucratividade da escravidão, as condições da oferta africana de cativos, que priorizava a venda de homens - impossibilitando, aliás, a reprodução natural ampliada da escravidão -, e a desproporção entre terra disponível e braços para ará-las. Necessariamente, o crescimento da economia brasileira requereu o uso predominante do trabalho escravo, na produção açucareira dos séculos XVI e XVII, nas minas do século XVIII, ou nas plantações de café do século XIX - além dos mais diversos setores da economia rural não-exportadora -, ou seja, a expansão da fronteira agrícola demandou o crescimento da escravidão. Sem esquecer o trabalho urbano, sobretudo o de "“escravos ao ganho', que vendiam produtos ou serviços por conta própria" (p. 150), ou dos escravos de aluguel.

Em resumo, esses variados usos dos escravos "criaram várias formas de autonomia, controle, incentivo, punições e relações entre escravos e senhores, entre cativos e pessoas livres" (p. 154). Evidentemente, a estrutura de posse de cativos se apresentou bem distinta de quadro repleto de senhores de enormes escravari- as, algo distinto da Jamaica. Essas variadas relações de trabalho geraram uma situação

atípica [singular] na sociedade escravista brasileira. Significativas taxas de alforria, muitas delas compradas pelos próprios cativos, aumentaram a população livre de origem africana, a qual, por sua vez, cresceu não apenas graças às alforrias, mas também a um generalizado processo de miscigenação ocorrido entre pessoas livres e escravas. A forma na qual a escravidão foi organizada no Brasil permitiu uma ampla socialização da população cativa e a formação de famílias, das quais algumas foram mantidas por gerações (p. 155).

Vida, morte, movimento de gente, rebelião, família, parentesco e livres de cor compõem os temas dos quatro capítulos da segunda parte. No capítulo 6, Luna e Klein abordam a dinâmica populacional a partir da influência do tráfico transatlântico (até 1850), que, evidentemente, impactou as taxas de natalidade, mortalidade e de alforria. $\mathrm{O}$ desequilíbrio sexual da escravaria (mais homens que mulheres) e a acentuada presença de africanos (que formavam a maioria dos escravos) geraram senzalas incapazes de se reproduzirem, com muitos adultos, majoritariamente do sexo masculino. Ademais, altas taxas de mortalidade, inclusive infantil, na escravaria não foram compensadas pelas de natalidade. As condições de oferta 
africana determinavam essa demografia desequilibrada no Brasil, pois as mulheres eram mais valorizadas em sociedades africanas, além de o tráfico, ao trazê-las adultas, roubar-lhes anos potenciais de procriação. Assim, indo muito além dos que insistem na tecla da pior ou mais deletéria escravidão brasileira, era principalmente a demografia do tráfico que inviabilizava a reprodução natural ampliada da escravaria. Pari passu, as alforrias também contribuíram - inclusive por favorecerem mulheres - para o não crescimento natural da população escrava, contrariamente ao da população livre de cor, sobretudo no Oitocentos.

Estes fatores acendem três pontos de debates: o imaginário decréscimo das alforrias no século XIX, o potencial reprodutivo das mulheres africanas escravizadas no Brasil e as condições da demanda brasileira como condicionantes primordiais da demografia escrava. ${ }^{6}$ Mais ainda. Os

\footnotetext{
Sobre o primeiro ponto,ver Ricardo Salles, E o Vale era o escravo: Vassouras - século XIX. Senhores e escravos no coração do Império, Rio de Janeiro: Civilização Brasileira, 2008. Para o segundo, José Roberto Góes e Manolo Florentino, A paz das senzalas: famílias escravas e tráfico atlântico, Rio de Janeiro, 1790-1850, Rio de Janeiro: Civilização Brasileira, 1997. Para o terceiro, Manolo Florentino, Em costas negras: uma história do tráfico entre a África e o Rio de Janeiro, séculos XVII e XIX, São Paulo: Companhia das Letras, 2010.
}

autores conduzem o leitor a se perguntar: se as africanas cativas pouco procriavam, quais os fatores, além da alforria, para que os livres de cor fossem o maior grupo populacional em 1872? Mulheres cativas, a maioria entre os alforriados, e suas descendentes, levavam sua fecundidade e fertilidade para a liberdade, ou as taxas de alforria eram elevadíssimas? Ou as duas coisas? Em quaisquer repostas, o mérito dos autores é estimular a reflexão.

"Resistência e rebelião no cativeiro" (capítulo 7) ressalta que a extrema dependência de uns homens em relação a outros inevitavelmente gera identidades entre os primeiros, no caso, "um sentimento de identidade e comunidade entre os escravos afrobrasileiros para sobreviverem como sociedade e como grupo", bem como "hostilidades fundamentais contra todo o sistema" (p. 203). Interessante também é a oscilação do Estado em proteger escravos, ao mesmo tempo em que legitimava o sistema. Mas, ao prevalecer o direito de propriedade, restou aos cativos a resistência, as fugas e atos de violência, ainda que fosse conservador o objetivo da maioria dos cativos fugidos: escapar da escravidão e levar uma vida normal como camponeses (p. 209). Mas também os quilombos estavam, em geral, fadados a não se reproduzir fisicamente. Fugir, no fim das contas, recurso de muitos escravos, diminuía 
as "pressões internas que normalmente se avolumavam em um regime escravista" (p. 215). Quando não era possível fugir, recorria-se à violência, em crimes contra senhores, parceiros, ou outros livres, brilhantemente analisada pelos autores. Não obstante variassem os motivos das ações hostis,

de modo geral se pode dizer que provavelmente a frequência com que cativos se envolviam em ataques contra outros cativos e contra pessoas livres em geral era igual à frequência com que eles cometiam crimes contra seus senhores ou feitores, e que, também com a mesma frequência, escravos figuravam como vitimas ou agressores (p. 217).

Rebeliões, igualmente, não tiveram motivação única. Porém, a violência "pairou sobre todos os membros da sociedade" escravista. Senhores, aliás, viveram

com seus medos constantemente expressos de rebeliões escravas, especialmente em comunidades com grande proporção de cativos na população (p. 224).

Novamente, os autores têm o mérito de conduzir o leitor à indagação: como foi possível um sistema social, constantemente amedrontado pela violência escrava, inflar, cada vez mais ao longo do tempo, portos, cidades e campos com milhões de cativos?

O capítulo 8, um contraponto ao anterior, salienta que fuga, resistência e violência não foram as únicas respostas à escravidão. Antes, a

maioria dos africanos e seus descendentes tentaram sobreviver à experiência do cativeiro e levar uma vida mais normal possível no contexto desse impiedoso sistema (p. 229).

Partindo das origens africanas dos cativos, Luna e Klein afirmam que a relevância cultural de uma determinada etnia não estava necessariamente associada à sua demografia. Sugerem que elementos culturais africanos, diferentes dos políticos, puderam se adaptar no escravismo brasileiro, mas permeados de catolicismo de origem europeia, também remodelado no Brasil. A estratificação social entre escravos e egressos do cativeiro emergiu desse amálgama, não obstante a imposição da hierarquia baseada na ocupação. Inevitável, portanto, a indagação sobre o que conferia, na comunidade escrava, status aos seus integrantes, que não necessariamente eram os mesmos elementos para as hierarquias entre livres e senhores. Autonomia sobre o tempo e o trabalho, familiaridade com elementos culturais e religiosos, percepção sobre os senhores, atuação como mediadores etc., geralmente conferiam distinções no seio da comunidade escrava. Atributos estes em geral encontrados entre os cativos com ocupação especializada. 
A par de clivagens entre os escravos, estes formavam uma comunidade que tinha na família o cerne de sua organização. Prevaleceram casamentos endogâmicos (crioulo casado com crioula, africano casado com africana), mas também altas taxas de ilegitimidade (uniões não realizadas na Igreja católica). Ilegitimidades maiores ou menores conforme o impacto do tráfico, o tamanho das escravarias, o meio urbano ou rural, mas com tendência de crescimento ao longo do século XIX. Com grandes variações regionais, a ilegitimidade era comum também a livres e forros, ainda que em menor grau. Não eram raros os casamentos mistos, entre escravos e livres de cor, e mesmo índios, e também não era raro o fato de todas estas uniões contribuírem para aumentar o número de braços para determinado senhor. Casados ou não, a maioria dos escravos vivia em famílias, que nem mesmo a morte do senhor e a consequente partilha da escravaria esfacelava, na maioria dos casos. Tal interpretação diverge da obra clássica de Florentan Fernandes, e de seus seguidores, que veementemente minimizou, quando não negou, o papel vivo da família escrava. ${ }^{7}$ Luna e Klein salientam o que ainda se pode avançar no tema do parentesco, como, por exemplo, a organização e a estabilidade internas. Sabe-

Florestan Fernandes, A integração do negro na sociedade de classes, São Paulo: Ática, 1978. se que o compadrio envolvendo escravos era corriqueiro. E era um parentesco misto, pois livres, forros e mesmo filhos de senhores também faziam parte dessa rede. Assim,

todos os estudos parecem indicar que esse foi um sistema de apoio eficaz que se tornou uma parte essencial da cultura afro-brasileira, tanto quanto o era da sociedade livre. Esse sistema de parentesco ritual intensificou os crescentes laços de amizade e comunidade entre os escravos e, dado o apreço da elite governante pelo compadrio, o sistema inclusive conferiu, entre os brancos, a legitimidade aos esforços dos negros para construir sua comunidade (p. 256).

Embora pareça contraditória a coexistência de senhores de vários matizes e de hierarquias internas aos escravos, de um lado, e a formação de comunidades escravas, criadores de uma cultura afro-brasileira, forjadas pela família e pelo compadresco, de outro, o certo é que um sistema de crenças também condicionou a formação de uma comunidade. Ocasionalmente, houve um processo de sincretismo e aculturação, trânsitos culturais, circularidades, como queiram. Pois, apesar de os

brancos temerem a autonomia das irmandades de negros e mulatos, estas, na maioria das vezes, aceitaram a cultura dominante e tiveram uma natureza principalmente integradora” (p. 262), 
uma "integração forçada à sociedade branca" (p. 263). Forçada porque sociedades escravistas eram

inevitavelmente racistas e rejeitaram a identidade e a dignidade negras, além de, em muitos casos, criarem uma cidadania de segunda classe para os que alcançavam a liberdade. A ascensão e a mobilidade social possíveis a um número de negros suficientes para incutir na maioria o sentimento de esperança, mas a condição para isso foi sempre a rejeição de sua negritude e da sua identidade cultural afro-americana. Diante dessa situação, era inevitável que as culturas estabelecidas pelos escravos nas Américas servissem a dois propósitos conflitantes: integrar os cativos à sociedade mais ampla dominada pelos brancos e dar-lhes uma identidade e um sentido que lhes protegessem da opressão e hostilidade dessa sociedade (p. 263).

Portanto, mesmo em uma sociedade que não era cindida entre senhores e escravos - com predomínio de senhores de pequenas posses, inclusive senhores forros, com ampla participação de livres de cor, maioria da população em muitos lugares - foi possível a construção de uma classe branca dominante, racista. Vai aí um certo anacronismo - pressupondo identidade afro-americana e de negritude antes do tempo - e um certo desconhecimento da historiografia brasileira a respeito do que significava ser branco no Brasil escravista, que estava longe de ser apenas cor da pele.

O capítulo 9 é instigante. Restrições à liberdade, estigmas de cor e de origem (africano, brasileiro), não impediram que as "pessoas livres de cor", incluindo os forros, se avolumassem a partir do século XVIII e compusessem a maior parcela da população em 1872. Assim, a mobilidade social, ainda que só até certo ponto, fez parte da realidade de tal população. Isto é fundamental, pois, embora todas as

colônias americanas fossem racistas e impusessem restrições à liberdade de ex-escravos, as sociedades que de fato se desenvolveram nos vários regimes escravistas diferiam acentuadamente. As diferenças relacionamse ao próprio processo de manumissão e à aceitação da legitimidade das pessoas livres de cor na ordem social e econômica mais ampla (p. 273).

O escravismo no Brasil produziu intensamente a alforria, de diversas formas e com variações regionais, bem como, por conseguinte, descendentes de cativos já nascidos livres. O comportamento social e o perfil demográfico da população forra e livre, inclusive suas relações com escravos, sua participação nas instituições etc., são brilhantemente analisados pelos autores, sobretudo suas taxas de fecundidade. Mas também vale muito a pena observar a atuação política ambivalente das elites de cor, atuando no movimento abolicionista, 
identificando-se "com seus semelhantes livres de cor e escravos" (p. 307), ao mesmo tempo em que agiam em prol da escravidão, da promoção do racismo, das diferenciações de cor. ${ }^{8}$ No último caso, um campo de pesquisa pouco explorado.

No desfecho, "embora atacada, desprezada, rejeitada e temida como uma classe de potenciais competidores, a classe das pessoas livres de cor nascidas no Brasil cresceu rapidamente sob o regime escravista que a criou". Foi sua "interminável batalha pela aceitação que [...] preparou o caminho para os escravos entrarem com melhores perspectivas na sociedade livre após a emancipação ser concedida a todos os africanos e afroamericanos", com "condições de integrar-se à economia de livre mercado" (p. 308). Vê-se aí um debate com a obra de Florestan Fernandes.

No capítulo 10, "A transição do cativeiro para a liberdade" é abordada, corretamente, a partir do impacto do fim do tráfico atlântico, em 1850. A Lei de 1831, que proibia a entrada de africanos escravos no país, teve "pouco efeito" (p. 328), ao menos demográfico. Assim, não há na obra nenhum protagonismo exagerado de

\footnotetext{
8 Veja-se o caso, para o período colonial, de pardos em confronto com mulatos nas irmandades. Larissa Moreira Viana, O idioma da mestiçagem: as irmandades de pardos na América portuguesa, Campinas: Editora da UNICAMP, 2007.
}

qualquer instituição, movimento ou grupo social para o fim da escravidão, sem os menosprezar. A diversidade regional da transição é a tônica do capítulo, que tematiza mercado de trabalho, racismo, impactos das culturas dos africanos reelaboradas por seus descendentes, no conjunto da população e na formação do Brasil, que adentrou o século XX.

$\mathrm{O}$ livro reflete o percurso intelectual dos autores, ao mesmo tempo em que demonstra um percurso historiográfico sobre a escravidão no Brasil. Por isso, há muitos méritos, mas também lacunas. A ênfase recai no século XIX e em áreas do Sudeste. A seleção da bibliografia deixou de fora obras clássicas de Gilberto Freyre, Caio Prado Junior e Florestan Fernandes. Talvez intencionalmente, pois estes autores, cujas ideias fizeram carreira na historiografia, deram, cada um a seu modo, pouca atenção ao mosaico senhorial, à dimensão da alforria, ao papel da população livre de cor etc. Nas palavras de Luna e Klein:

A complexidade do sistema escravista brasileiro vem sendo lentamente revelada através da abertura gradual de arquivos locais e provinciais por historiadores e outros cientistas sociais, e mostra um mundo muito mais rico e complexo do que aquele apresentado por Gilberto Freyre (p. 356).

Com efeito, como já se ressaltou, autores de uma mesma época, dos anos 1920 aos 40, 
e Gilberto Freyre em particular, buscavam entender a origem do caráter brasileiro nos engenhos. Fizeram a história de um ideal [...]. O com que eles não estavam preocupados, e nós estamos agora, é justamente a organização e a atuação dos diversos grupos no conjunto social. ${ }^{9}$

Mas Luna e Klein vão bem além disso. Sua erudição lhes permite analisar tais aspectos, e isto é fundamental em uma obra de síntese e de visão de conjunto, incluindo outras sociedades escravistas das Américas. Não há um capítulo em que a comparação, em busca de uma interpretação abrangente, deixe de ser empregada. A perspectiva de totalidade, sem cair em generalidades, é, sem dúvida, uma das melhores contribuições do livro, doravante leitura obrigatória em cursos de graduação e pós-graduação, mas também recomendável ao público mais amplo.

Roberto Guedes Universidade Federal Rural do Rio de Janeiro

9 Sheila de Castro Faria, A colônia em movimento: fortuna e família no cotidiano colonial, Rio de Janeiro: Nova Fronteira, 1998 pp. 47-49. 